\title{
PENERAPAN PEMBELAJARAN AKTIF DENGAN METODE PERMAINAN BINGO UNTUK MENINGKATKAN HASIL BELAJAR MATEMATIKA
}

\author{
Tian Oktaviani ${ }^{1}$, Endah Rita Sulistya Dewi ${ }^{2}$, Kiswoyo ${ }^{3}$ \\ 1,3 Jurusan Pendidikan Guru Sekolah Dasar Universitas PGRI Semarang \\ 2Jurusan Pendidikan Biologi Universitas PGRI Semarang \\ e-mail: tianoktaviani01@gmail.com ${ }^{1}$
}

\begin{abstract}
Abstrak
Tujuan dari penelitian ini adalah untuk mengetahui penerapan pembelajaran aktif dengan metode permainan bingo untuk meningkatkan hasil belajar matematika. Latar belakang yang menggerakkan penelitian ini adalah rendahnya hasil belajar matematika siswa, yang menurut sebagian siswa, matematika adalah pelajaran yang sulit dipahami sehingga aktivitas belajar siswa pada mata pelajaran Matematika menurun. Faktor lain yang mempengaruhi hasil belajar siswa dalam Matematika adalah kurangnya guru dalam menggunakan metode pembelajaran. Metode pembelajaran yang digunakan cenderung monoton dan siswa merasa bosan ketika pembelajaran berlangsung. Jenis penelitian ini adalah kuantitatif. Metode penelitian Desain Pra-Eksperimental, dengan desain penelitian One-Group Pretest-Posttest Design. Populasi dalam penelitian ini adalah siswa SD Negeri Kedungjenar, Kabupaten Blora, sedangkan untuk sampelnya adalah siswa kelas $\mathrm{V}$ yang terdiri dari 3 kelas dan jumlah 108 siswa. Data penelitian diperoleh dengan menggunakan item item untuk pretest dan posttest. Hasil analisis penelitian mengungkapkan bahwa hasil persentase pretest siswa dari hasil belajar siswa adalah sebesar $51,13 \%$ sedangkan hasil posttest siswa setelah dirawat dengan permainan bingo persentase hasil belajar siswa menjadi $72,66 \%$. Pembelajaran aktif dengan metode permainan bingo dapat menciptakan lingkungan belajar yang menyenangkan, di mana siswa akan menjadi aktif dalam proses pembelajaran, lebih mampu bekerja dengan teman-teman lain, suasana kelas lebih hidup dan mampu mencapai tujuan pembelajaran yang diinginkan. Sehingga siswa akan termotivasi untuk bersaing sehat dan siswa tidak merasa bosan selama proses pembelajaran. Kesimpulan dari penelitian ini adalah penerapan pembelajaran aktif dengan metode permainan bingo dapat meningkatkan hasil belajar matematika.
\end{abstract}

Kata-kata kunci : hasil belajar, pembelajaran aktif, permainan bingo.

\begin{abstract}
The purpose of this study was to determine the application of active learning with the method of bingo games to improve mathematics learning outcomes. The background that drives this research is the low student mathematics learning outcomes, which according to some students, mathematics is a difficult lesson to understand so that student learning activities on subjects Mathematics is decreasing. Another factor that influences student learning outcomes in Mathematics is the lack of teachers in using learning methods. Learning methods used tend to be monotonous and students feel bored when learning takes place. This type of research is quantitative. Pre-Experimental Design research method, with research design One-Group Pretest-Posttest Design. The population in this study were students of SD Negeri Kedungjenar, Blora Regency, while for the sample were the fifth grade students consisting of 3 classes and a total number of 108 . The research data was obtained by using item items for pretest and posttest. The results of the research analysis revealed that the results of the students' pretest percentage of student learning outcomes amounted to $51.13 \%$ while the posttest results of students after being treated with bingo games the percentage of student learning outcomes became $72.66 \%$. Active learning with the method of bingo games can create a pleasant learning environment, where students will become active in the learning
\end{abstract}


process, more able to work with other friends, the atmosphere of the class is more alive and able to achieve the desired learning goals. So that students will be motivated to compete healthy and students do not feel bored during the learning process. The conclusion of this study is the application of active learning with the method of bingo games can improve mathematics learning outcomes.

Keywords: learning outcomes, active learning, bingo games

\section{Pendahuluan}

Pendidikan adalah suatu proses atau kegiatan dimana seorang pendidik dan peserta didik melakukan interaksi untuk mengembangkan kemampuan, sikap dan potensi peserta didik guna mencapai tujuan pendidikan. Menurut Undang-Undang Republik Indonesia Nomor 20 Tahun 2003 tentang Sistem Pendidikan Nasional: "Pendidikan adalah usaha sadar dan terencana untuk mewujudkan suasana belajar dan proses pembelajaran agar peserta didik secara aktif mengembangkan potensi dirinya untuk memiliki kekuatan spiritual keagamaan, pengendalian diri, kepribadian, kecerdasan, akhlak mulia, serta ketrampilan yang diperlukan dirinya, masyarakat, bangsa dan Negara".

Sesuai dengan Undang-Undang RI No. 20 Tahun 2003 tentang Fungsi Pendidikan Nasional Bab II yang berbunyi : Pendidikan Nasional berfungsi mengembangkan dan membentuk watak serta peradaban bangsa yang bermartabat dalam rangka mencerdaskan kehidupan bangsa, bertujuan untuk mengembangkan potensi peserta didik agar menjadi manusia yang beriman dan bertaqwa kepada Tuhan Yang Maha Esa, berakhlak mulia, sehat, berilmu, cakap, kreatif, mandiri dan menjadi warga negara yang demokratis dan bertanggung jawab. Fungsi tersebut dapat di peroleh melalui proses pembelajaran, dan pembelajaran itu sendiri dapat diartikan sebagai proses belajar mengajar antara guru dan peserta didik dalam proses peningkatan kemampuan baik di ranah kognitif, afektif maupun ketrampilan. Maka dari itu seorang guru harus menerapkan pembalajaran yang aktif, inovatif, kreatif, efektif dan menyenangkan agar peserta didik tidak merasa jenuh saat proses pembelajaran. Menurut Hamzah dan Nurdin (2015:10) Aktif dalam pembelajaran adalah memosisikan guru sebagai orang yang menciptakan suasana belajar kondusif atau sebagai fasilitator dalam belajar,sementara siswa sebagai peserta belajar yang harus aktif. Dalam proses pembelajaran yang aktif terjadi dialog yang interaktif antara siswa dengan siswa, siswa dengan guru atau siswa dengan sumber belajar lainnya. Menurut Hamzah dan Nurdin (2015:77) menyatakan bahwa strategi pembelajaran yang aktif dalam proses pembelajaran adalah siswa diharapkan aktif terlibat dalam proses pembelajaran untuk berpikir, mencoba, membuat menemukan konsep baru, dan menghasilkan suatu karya. Sesuai dengan kurikulum yang digunakan saat ini yaitu kurikulum 2013 yang meharuskan siswa aktif dalam proses pembelajaran atau student center learning. Salah satu cara yang bisa diterapkan dalam pembelajaran aktif yaitu dengan menggunakan metode yang sesuai dengan karakteristik siswa saat ini. Melalui metode pembelajaran, siswa akan lebih mudah dalam menerima informasi dalam proses pembelajaran. Menurut Joyce dan Weil (dalam Uno dan Hamzah 2015: 219) mengemukakan bahwa model pembelajaran adalah suatu rencana atau pola yang digunakan untuk membentuk rencana pembelajaran guna mencapai tujuan pembelajaran tersebut.

Siswa akan menjadi aktif, tertarik dan antusias dalam pelajaran, jika guru mampu menerapkan metode pembelajaran yang kreatif serta menyenangkan. Pada kenyataannya dilapangan masih terdapat beberapa persoalan, salah satunya yaitu masih rendahnya hasil belajar siswa khususnya pada mata pelajaran Matematika. Menurut sebagian siswa, matematika merupakan pelajaran yang sulit dimengerti sehingga aktivitas belajar siswa pada mata pelajaran Matematika menjadi menurun. Faktor lain yang mempengaruhi hasil belajar siswa akan pelajaran Mamematika adalah kurangnya guru dalam menggunakan metode pembelajaran. Metode pembelajaran yang digunakan cenderung monoton dan siswa merasa bosan saat pembelajaran berlangsung. Kurangnya hal tersebut menyebabkan kurang 
optimalnya hasil belajar matematika yang belum mencapai KKM. Nilai rata-rata matematika siswa kelas V di SD Kedungjenar Kabupaten Blora yaitu 61 dari standar nilai KKM yaitu 75. Dilihat dari nilai rata-rata yang diperoleh siswa, maka hasil belajar matematika belum dikatakan baik untuk mencapai target KKM yang ditentukan. Menurut Nana Sudjana( dalam Hasan Baharun 2015:39) hasil belajar adalah kemampuan-kemampuan yang dimiliki siswa setelah ia menerima pengalamannya. Berdasarkan hal tersebut, maka guru mempunyai tugas untuk menciptakan pembelajaran yang kreatif dan aktif dengan menggunakan metode yang menarik. Dengan pembelajaran yang demikian, diharapkan tujuan pembelajaran dapat tercapai dengan maksimal.

Salah satu pembelajaran yang dapat menarik perhatian siswa yaitu dengan menggunakan metode permainan. Dengan menggunakan metode permainan, siswa lebih merasa senang saat pelajaran berlangsung. Metode permainan yang dapat diterapkan adalah metode permainan bingo. Menurut Siberman (dalam Dinar dan Vicky 2012 : 2) bingo merupakan permainan berupa tabel bernomor, ketika siswa dapat menjawab soal lima deret secara horizontal, vertikal maupun diagonal maka kelompoknya akan menang dan mendapat poin yang berpengaruh terhadap nilai kelompok. Permainan bingo merupakan salah satu cara yang bisa digunakan dalam memecahkan masalah yang ada pada pelajaran contohnya yaitu pelajaran matematika. Dengan menggunakan simulasi permainan di tengah-tengah pembelajaran, diharapkan siswa lebih merasa senang dan paham akan pelajaran yang disampaikan. Manfaat lain dari permainan bingo pada pembelajaran yaitu dapat menciptakan interaksi positif antara siswa dan guru serta siswa dapat belajar akan sikap toleransi dan menghargai pendapat orang lain. Dengan menerapkan pembelajaran aktif metode permainan bingo diharapkan siswa yang menganggap pelajaran matematika sulit dan membosankan berubah menjadi pelajaran yang menyenangkan dan tidak menakutkan.

McMahon (2017), Permainan bingo modern merupakan permainan lotere dari orang Italia yang biasa disebut sebagai Lo Giuocodel Lotto d'Italia. Permainan bingo adalah permainan tentang kesempatan. Ketika dimainkan dalam kelompok, permainan bingo dapat aktivitas kolaborasi (Shafia, 2018). Siswa berpartisipasi dalam kelompok akan aktif terlibat dalam pembelajaran, menguatkan pemahamann siswa, memanfaatkan kemampuan berpikir kritis mereka untuk mengenali kelebihan dan kekurangan dari materi, dan mengembangkan keterampilan komunikasi interaktif siswa. Selain karena kegunaannya yang telah diuraikan di atas, alasan pemilihan permainan bingo sebagai media yang akan dikembangkan adalah karena pembelajaran menggunakan media permainan bingo pada materi reaksi redoks belum pernah dilakukan.

Beberapa penelitian menunjukkan hasil yang positif terhadap aplikasi media permainan bingo dalam proses pembelajaran. Penelitian Mawati, (2013) menunjukkan bahwa siswa sangat setuju dengan permainan yang digunakan dalam kegiatan belajar di kelas serta memperoleh rata-rata hasil belajar sebesar 88.25 dari 36 siswa pada kelas ekperimen dengan permainan bingo. Selain itu, menurut Halifah, (2015) Penggunaan permainan Bingo pada materi konsep mol memberikan pengaruh terhadap hasil belajar sebesar $23.89 \%$. Terdapat perbedaan motivasi belajar siswa antara kelas kontrol dan kelas eksperimen

\section{Metode}

Metode yang akan digunakan dalam penelitian ini adalah Pre-Experimental Design, karena dalam desain ini belum merupakan eksperimen sungguh-sungguh. Jadi hasil eksperimen yang merupakan variabel dependen itu bukan semata-mata dipengaruhi oleh variabel independen. Desain penelitian yang akan dilakukan dalam penelitian ini adalah OneGroup Pretest-Posttest Design. Sugiyono (2016 : 114), dalam desain ini terdapat pretest sebelum diberiperlakuan. Dalam penelitian ini akan menggunakan teknik Sampling Purposive yaitu teknik penentuan sampel dengan pertimbangan tertentu. Jadi sampel yang akan digunakan dalam penelitian ini sebanyak 30 siswa kelas VC yang dipilih dengan pertimbangan tertentu. 


\section{Hasil dan Pembahasan}

Berdasarkan hasil penelitian, peneliti dapat memperoleh data penelitian dan pembahasan tentang "Penerapan Pembelajaran Aktif Dengan Metode Permainan Bingo Untuk Meningkatkan Hasil Belajar Matematika Siswa Kelas V SDN Kedungjenar Kabupaten Blora". Sebelum melakukan penelitian, peneliti melakukan observasi terlebih dahulu ke sekolah, untuk mengetahui masalah-masalah apa saja yang ada di sekolah tersebut. Setelah peneliti mengetahui permasalahannya, peneliti melakukan wawancara dengan guru kelas dan sebagian siswa yang akan diteliti. Penelitian dilakukan di kelas $\mathrm{V}$ dengan jumlah sampel sebanyak 30 siswa diambil dari kelas VC. Sebelum melakukan penelitian, peneliti melakukan tryout di kelas VB untuk mengetahui validitas dan reabilitas instrumen penelitian. Berdasarkan hasil tryout, item yang valid sebanyak 30 soal dari 40 soal yang di uji cobakan. Setelah dilakukan tryout, peneliti melakukan prettes untuk mengetahui kondisi awal dari subjek tersebut. Pada uji persyaratan data yaitu uji normalitas dengan menggunakan uji Lillifors diperoleh hasil perhitungan prettest dengan nilai $L o=0,064$ dan $L$ tabel $=0,161$ karena $L o<$ $\mathrm{L}$ tabel yaitu $0,064<0,161$ maka Ho diterima. Sehingga dapat disimpulkan bahwa hasil pretest berasal dari populasi yang berdistribusi normal. Kemudian dilanjutkan dengan pemberian perlakuan dengan menggunakan permainan bingo. Perlakuan dilakukan sebanyak 4 kali pertemuan. Dimana setiap pertemuan diberi jeda sehari. Pertemuan pertama dilaksanakan pada tanggal 25 Maret 2019, Pertemuan kedua pada tanggal 27 Maret 2019, pertemuan ketiga pada tanggal 29 Maret 2019 dan pertemuan terakhir dilaksanakan pada tanggal 1 April 2019. Pada pertemuan pertama dan kedua peneliti tidak memberikan perlakuan apa-apa dengan maksud agar bisa mengetahui adanya perbedaan hasil belajar sebelum dan sesudah diberi perlakuan. Kemudian pertemuan ketiga dan keempat peneliti memberi perlakuan dengan menggunakan permainan bingo dengan harapan setelah diberi perlakuan hasil belajar matematika siswa akan meningkat dari sebelumnya. Kemudian peneliti melakukan posstest untuk mengetahui kondisi subjek setelah diberikan perlakuan. Setelah uji normalitas pada pretest, peneliti juga melakukan uji normalitas posttest yang diperoleh Lo yaitu sebesar 0,155 dan $L$ tabel 0,161 karena $L o<L$ tabel yaitu $0,155<0,161$ maka Ho diterima dan dapat disimpulkan data berdistribusi normal. Kemudian pada uji hipotesis dengan menggunakan Paired Sample t Test diperoleh hasil perhitungan t hitung sebesar 9,488 dan t tabel 1,672 karena $t$ hitung $>$ t tabel yaitu 9,488 > 1,672 maka Ho ditolak dan Ha diterima. Jadi dapat disimpulkan bahwa penerapan pembelajaran aktif dengan metode permainan bingo dapat meningkatkan hasil belajar matematika siswa kelas V SDN Kedungjenar Kabupaten Blora.

Berdasarkan analisis data yang telah dijabarkan, maka dalam pembahasan ini akan dijelaskan mengenai hasil analisis data sebagai berikut. Data tes yang digunakan adalah dalam bentuk soal prettest dan posttest. Hasil prettest menunjukan bahwa nilai rata-rata matematika kelas $\mathrm{V}$ yaitu 51,13 dan nilai rata-rata posttest matematika kelas $\mathrm{V}$ yaitu 72,66 . Hal ini menunjukkan bahwa hasil belajar siswa meningkat dari yang sebelum diberi perlakuan dan sesudah diberi perlakuan. Data tersebut juga ditunjukkan dengan hasil perhitungan uji $t$, dimana nilai t hitung yaitu 9,488 dan nilai t tabel 2,000. Jadi, nilai t hitung $>t$ tabel. Sehingga Ho ditolak dan $\mathrm{Ha}$ diterima, yang menjelaskan bahwa pembelajaran aktif dengan metode permainan bingo dapat meningkatkan hasil belajar matematika siswa kelas V SD Negeri Kedungjenar Kabupaten Blora. Berdasarkan analisis diatas yang diperoleh dari data yang sudah terkumpul, dapat diketahui bahwa pembelajaran aktif dengan metode permainan bingo dapat meningkatkan hasil belajar matematika, karena dengan bermain sambil belajar dapat menggugah minat siswa dalam mengikuti proses pembelajaran. Hal tersebut sejalan dengan penelitian yang dilakukan oleh Luluk dan Asto (2013) yang menyatakan bahwa penelitian yang menggunakan permainan bingo dalam model pembelajaran Kooperatif tipe Nht dapat meningkatkan hasil belajar siswa, hal ini menggambarkan bahwa hasil penelitian dengan menggunakan soal post-test yang dilakukan oleh kelas eksperimen dengan menggunakan permainan bingo memiliki hasil belajar lebih baik daripada hasil belajar kelas kontrol yang tidak menggunakan permainan bingo. Selanjutkan penelitian yang dilakukan oleh Zainudin (2015) yang berjudul "Meningkatkan Hasil Belajar Siswa Pada Mata Pelajaran Fiqh Melalui 
Penerapan Strategi Bingo". Menunjukkan bahwa dengan menerapkan permainan bingo dapat meningkatkan aktivitas dan hasil belajar siswa. Dimana dalam proses pembelajaran siswa merasa senang, termotivasi saat belajar dan siswa lebih memahami materi yang disampaikan oleh guru tersebut. Hal tersebut diperoleh dari hasil angket siswa yang menunjukkan respon positif terhadap permainan bingo.

Berdasarkan penelitian yang telah dilakukan di SD Negeri Kedungjenar Kabupaten Blora diperoleh fakta dimana penerapan pembelajaran aktif dengan metode permainan bingo dapat meningkatkan hasil belajar matematika siswa kelas V SD Negeri Kedungjenar Kabupaten Blora. Dimana dalam permainan bingo tersebut, siswa dibentuk secara berkelompok untuk bekerja sama menjawab soal yang diberikan oleh guru. Secara tidak langsung siswa akan lebih bersemangat menjawab soal-soal yang diberikan oleh guru tersebut. Salah satu alasannya karena setiap kelompok yang berhasil menjawab dengan benar, bisa menempelkan bintang di papan bingo dan akan diberikan poin lebih oleh guru. Kelompok yang berhasil menjawab pertanyaan lebih banyak dari kelompok lain yaitu berhasil menempelkan bintang sebanyak tiga beruturut-turut secara horizontal, vertikal, maupun diagonal dapat dikatakan sebagai pemenang dan akan diberi reward oleh guru berupa hadiah, dengan begitu siswa lebih aktif bekerja sama dengan kelompoknya untuk mendapatkan poin yang lebih banyak. Karena dalam hal ini, kelebihan dari permainan bingo yaitu dapat melatih siswa untuk bekerja sama dengan temannya, dapat mengahargai pendapat orang lain, siswa lebih aktif pada saat pembelajaran dan suasana pembelajaran yang berlangsung juga lebih hidup dan guru mampu mencapai tujuan pembelajaran yang diinginkan.

\section{Simpulan dan Saran}

Berdasarkan penelitian yang telah dilakukan di SD Negeri Kedungjenar Kabupaten Blora, di awali dengan observasi, menyusun latar belakang masalah kemudian dilanjutkan dengan menyebar instrumen penelitian hingga analisis data hasil penelitian, maka dapat disimpulkan bahwa penerapan pembelajaran aktif dengan metode permainan bingo dapat meningkatkan hasil belajar matematika siswa kelas V SD Negeri Kedungjenar Kabupaten Blora.Dimana pada perhitungan uji $\mathrm{T}$ diperoleh hasil dimana nilai t hitung yaitu 9,488 dan nilai $t$ tabel 2,000. Jadi, nilai $t$ hitung $>\mathrm{t}$ tabel. Sehingga Ho ditolak dan Ha diterima, yang menjelaskan bahwa pembelajaran aktif dengan metode permainan bingo dapat meningkatkan hasil belajar matematika siswa kelas V SD Negeri Kedungjenar Kabupaten Blora.

Saran yang dapat disampaikan berdasarkan penelitian yang telah dilakukan adalah sebagai berikut. 1) Siswa di sekolah dasar agar dapat aktif dalam proses pembelajaran dan menggali banyak informasi yang tidak terbatas pada buku, ceramah guru di dalam kelas. Selain itu juga dapat menemukan solusi atas permasalahan yang dialami dalam proses interaksi dengan lingkungan. 2) Guru di sekolah dasar agar aktif berinovasi dalam merancang proses pembelajaran melalui penerapan model pembelajaran yang inovatif dan didukung media pembelajaran yang relevan guna meningkatkan ketertarikan siswa untuk belajar sehingga dapat meningkatkan hasil belajar siswa. 3) Sekolah yang mengalami permasalahan rendahnya hasil belajar IPS, disarankan untuk mengimplementasikan model pembelajaran yang lebih relevan dengan perkembangan zaman dan teknologi masa kini. 4) Peneliti yang berminat untuk mengadakan penelitian lebih lanjut agar memperhatikan kendala-kendala yang dialami dalam penelitian ini sebagai bahan pertimbangan untuk mengadakan perbaikan dan penyempurnaan penelitian yang hendak dilaksanakan.

\section{Daftar Pustaka}

Arikunto, Siharsimi. 2014. Prosedur Penelitian Suatu Pendekatan Praktik. Jakarta: PT Rineka Cipta.

Halifah, S. S. 2015. Pengaruh Teknik Permainan Bingo Pada Materi Konsep Mol Terhadap Hasil Belajar dan Motivasi Di SMA. Artikel. Untan 
Hapsari, Dinar dan Vicky Dwi Wicakson. 2012. "Pengaruh Metode Permainan Bingo Terhadap Motivasi Dan Pemahaman Materi Ppkn Kelas Iv Sdn Sumokembangsri Sidoarjo". Jurnal PGSD, Volume. 1, Nomor. 5. Hal 1-11.

Herlina. 2015. "Meningkatkan Pemahaman Kosakata Bahasa Inggris Melalui Metode Permainan Bingo". Jurnal IImiah VISI PPTK PAUDN, Volume. 10, Nomor. 2. Hal 114121.

Mawati, L. 2013. Pengaruh Permainan Bingo Dalam Model Pembelajaran Kooperatif Tipe NHT Terhadap Hasil Belajar Siswa Pada Standar Kompetensi Menerapkan Dasar Dasar Teknik Digital di SMKN 1 Jetis Mojokerto. Jurnal Pendidikan Teknik Elektro, Vol 2 No 2 Hal.707-714

McMahon, J. M. 2017. An Organizational Structure Game (And BINGO! Is Its Name-O). Management Teaching review1-9. Journals@sagepub.com

Purwanto. 2014. Belajar dan Faktor-faktor Yang Mempengaruhi. Jakarta: PT Raja Grafindo Persada.

Shafia, D., Nazar, M. and Ismayani, A., 2018. PENGEMBANGAN MEDIA PERMAINAN BINGO PADA MATERI KONSEP REAKSI REDOKS UNTUK SISWA KELAS X SMA LABORATORIUM UNSYIAH. Jurnal IImiah Mahasiswa Pendidikan Kimia, 3(2).

Sholikah, Luluk Mawati dan Asto Buditjahjanto. 2013. "Pengaruh Permainan Bingo Dalam Model Pembelajaran Kooperatif Tipe Nht Terhadap Hasil Belajar Siswa Pada Standar Kompetensi Menerapkan Dasardasar Teknik Digital Di Smkn 1 Jetis Mojokerto". Jurnal Pendidikan Teknik Elektro, Volume. 2, Nomor. 2. Hal 707-714.

Slameto. 2010. Belajar dan Faktor-faktor Yang Mempengaruhi. Yogyakarta: Pustaka Pelajar.

Sudjana. 2005. Metoda Statistika. Bandung: Tarsito.

Sugiyono, 2018. Metode Penelitian Pendidikan. Bandung: Alfabeta.

Sugiyono. 2018. Metode Penelitian Kuantitatif, Kualitatif dan R\&D.. Bandung: Alfabeta.

Uno, Hamzah. B. Nurdin Mohamad. 2015. BELAJAR DENGAN MENGGUNAKAN PENDEKATAN PAILKEM: Pembelajaran Aktif, Inovatif, Ligkungan, Kreatif, Efektif dan Menarik. Jakarta: Bumi Aksara.

Warsono, Hariyanto. 2013. Pembelajaran Aktif. Bandung: PT Remaja Rosdakarya.

Zainudin. 2015. "Meningkatkan Hasil Belajar Siswa Pada Mata Pelajaran Fiqh Melalui Penerapan Strategi Bingo" . Jurnal Penelitian Pendidikan Islam, Volume. 10, Nomor. 2. Hal 301-318. 